\title{
PERCEPÇÕES DE PROFESSORAS/ES DE PORTUGUÊS SOBRE SEXUALIDADE E(M) SUAS AULAS NO ENSINO MÉDIO
}

\author{
PORTUGUESE TEACHERS' PERCEPTION ABOUT SEXUALITY IN THEIR HIGH \\ SCHOOL CLASSES
}
Rodrigo dos Santos Dantas da Silva1 , Catarina Dallapicula²
1 Secretaria do Estado do Espírito Santo (Sedu/ES), Brasil, e-mail: dyghusoueu@gmail.com, ORCID: https://orcid.org/0000-0001-7993-7303
${ }^{2}$ Departamento de Psicologia da Educação e Metodologia da Pesquisa da Faculdade de Educação da Universidade do Estado de Minas Gerais (UEMG), cdallapicula@hotmail.com, ORCID: https://orcid.org/0000-0002-0595-3236

\author{
AR T I C LE INFO \\ Article history: \\ Received 2020-06-01 \\ Accepted 2020-11-30 \\ Available online 2020-11-30
}

Palavras-chave: Sexualidade. Currículo. Português.
Ensino.Professores.

Keywords: Sexuality. Curriculum. Portuguese. Teaching. Theachers.

RESUMO. O presente estudo foi realizado em 2017 e foi apresentado como Trabalho de Conclusão do Curso Especialização em Direitos Humanos, ofertado pela Universidade Federal do Espírito Santo (Ufes) entre os anos de 2016 e 2017. O mesmo configura-se na análise de percepções de professores de língua portuguesa do Ensino Médio, que atuavam em Ecoporanga /ES, e o processo educativo acerca da sexualidade por meio desta disciplina. A pesquisa em questão tende a perceber o ensino da temática transversal da sexualidade na disciplina escolar de língua portuguesa. A produção de informações aconteceu por meio da estratégia de grupo focal e um aporte teórico que compreende os conceitos de currículo, ensino acerca da sexualidade e a importância da linguagem na vida dos sujeitos. É um texto que enfatiza as vivências de profissionais de língua materna em sala de aula ao expor as angústias deles acerca do ensino da sexualidade nas escolas.

ABSTRACT. The present study was carried out in 2017 and presented as Conclusion Work for the Specialization Course in Human Rights, offered by the Federal University of Espírito Santo (Ufes) between the years 2016 and 2017. The same is configured in the analysis of teachers. 'perceptions of high school students of Portuguese language, who worked in Ecoporanga / ES, and the educational process on sexuality through this discipline. The research in question tends to perceive the teaching of the transversal theme of sexuality in the school discipline of the Portuguese language. The production of information occurred through the focus group strategy and a theoretical contribution that comprises the concepts of curriculum, teaching on sexuality and the importance of language in the lives of the subjects. It is a text that emphasizes the experiences of mother tongue professionals in the classroom, exposing their anxieties about teaching sexuality in schools.

\section{Introdução}

Esse artigo é uma pequena parte do Trabalho de Conclusão do Curso de Especialização em Direitos Humanos ofertado pela Universidade Federal do Espírito Santo (UFES), e apesar de enfatizar a sexualidade, sabemos que é preciso mover um olhar completo 
sobre os indivíduos e suas interações dentro da escola - onde as mesmas são subsídios para a investigação das possíveis implicações existentes nas relações entre gênero, sexualidade e interação social. Eckert e MacConnell-Ginet veem a identidade de gênero como "valor simbólico da forma linguística que está sendo constante e mutuamente construído", (OSTERMANN; FONTANA, 2010) e, portanto, não deve ser excluída das práticas sociais, seja dentro ou fora da escola.

Para FOUCAULT (2014), a sexualidade marcou nos dois séculos primeiros séculos de nossa era um reforço de temas de austeridade. Médicos, filósofos o cristianismo, assim como o capitalismo, naquele contexto tratava a sexualidade como um mal, se esta estivesse fora dos moldes conjugais. Traçando desta forma a "moral" diante questões sexuais dos dias de hoje.

Percebemos que a sexualidade é subjetiva e se manifesta em todas as lacunas de um ser, inclusive nos processos de educação. No entanto, vê-se também que indivíduos com sexualidades não hegemônicas sempre foram oprimidos nos educandários. Por isso, em 2017, resolvemos nos "juntar" com outros professores de língua portuguesa da Rede Estadual do Espírito Santo para saber quais suas percepções sobre a sexualidade em sala de aula e se a temática é trabalhada em algum momento. E se não o fazem, tentamos entender o porquê deste apagamento. A escola precisa compreender que o corpo ultrapassa aquilo que conhecemos acerca dele, (DELEUZE, 2002).

Esse estudo foi realizado em Ecoporanga/ES no ano de 2017 e naquele momento o município possuía seis escolas estaduais, sendo que quatro delas ofertavam o Ensino Médio. Pensando neste contexto, foi feita uma análise do Currículo Básico Comum, CBEE, pertinente às escolas capixabas, e notamos que na disciplina de Língua Portuguesa a sexualidade é ignorada nas três séries do Ensino Médio - contemplada apenas na 3ª série com o estudo das literaturas homoerótica e feminista e num conteúdo chamado de "afirmação da diferença".

Pensamos que o tema pode ser abordado em todas as séries desta modalidade educacional e em diversos conteúdos: no uso dos pronomes pelos vários tipos de sujeitos do nosso dia a dia, na abordagem gramatical, literária e textual - instigando reflexões sobre as mudanças dos posicionamentos feminino e masculino dos indivíduos até chegarmos à contemporaneidade.

Entrou-se em contato com professores de português que na época atuavam no município citado, a fim de ouvi-los sobre suas ações na prática cotidiana docente que diz respeito à sexualidade, com o objetivo de promover uma troca de experiências. Para unir essas percepções foi usada a metodologia de grupo focal com esses profissionais.

Vemos que o CBEE, antes Currículo Básico Comum (CBC), é um currículo que não há neutralidade, possui caráter heteronormativo e não nos dá subsídios para o trabalho cotidiano no ensino de português acerca da sexualidade. Esse 'bloqueio curricular' resulta da 
estruturação heteronormativa que comunga nossa sociedade: são preceitos religiosos, padrões a serem seguidos e hierarquizações desnecessárias que perduram pela sociedade brasileira desde os tempos coloniais.

Parece uma fala clichê, mas é a Educação o instrumento crucial capaz de modificar os olhares ameaçadores para aquilo que é considerado fora do padrão pela grande maioria - e quando falo dessas considerações, não penso apenas na sexualidade dos seres, coloco em pauta as diferenças regionais, de raça, as formas de vestir e portar dos diversos indivíduos. Nossa sexualidade, assim como nossos corpos e atitudes são nossos artifícios políticos para nos autoafirmarmos em nosso meio, assim:

[...] temos propósitos políticos comuns e que compartilhamos de um mesmo campo, a Educação, para dar vida a esses propósitos. É provável que compartilhemos algumas referências teóricas, mas, ao mesmo tempo, perseguimos nossos propósitos políticos através de estratégias, teorias e táticas muitas vezes distintas e, eventualmente, divergentes (LOURO, p. 205, 2007).

As múltiplas sexualidades devem ser compreendidas como problemas ou questões da sociedade e da cultura (LOURO, 2007). Por isso é necessário problematizar a heterossexualização presente nas esferas sociais, como por exemplo, a escola. Sexo geralmente é um tema muitas vezes trabalhado na escola durante as aulas de ciências e biologia, enfatizando apenas o sistema reprodutor e a anatomia dos corpos. Por isso, a relevância desse trabalho é trazer discussões sobre sexualidade durante o ensino de português, levando em consideração as vivências dos professores da referida disciplina.

A realização dessa pesquisa repensa a dinâmica da produção de currículo do ensino de português levando em consideração o contexto de nossos alunos e a prática de professores. Pretendemos também perceber o ensino da sexualidade, quando ele ocorre, durante o ensino de português e perceber os fatores que levam ao ignorar dessa temática durante o processo de ensino-aprendizagem no Ensino Médio.

\section{Currículo e sexualidade}

Antes de adentrar em qualquer representação que envolva o trabalho com português em sala de aula, é preciso conceituar currículo. Segundo Tanner (1975, apud LOPES; MACEDO, 2011, p. 20):

O currículo é definido como as experiências de aprendizagem planejadas e guiadas e os resultados de aprendizagem planejadas e guiadas e os resultados de aprendizagem não desejados formulados através da reconstrução sistemática do conhecimento e da experiência sob os 
auspícios da escola para o crescimento contínuo e deliberado da competência pessoal e social do aluno (LOPES; MACEDO, 2011, p. 20).

Ratifica-se Tanner, ressaltando que os resultados dos processos educativos não podem visar uma formação imperecível e comum a todos os sujeitos da pós-modernidade, a fim de que eles reproduzam aquilo que aprenderam tão qual como foram ensinados. Nós, professores, ao analisarmos grade comum às instituições capixabas de ensino, retiramos deles os conteúdos que julgamos pertinentes ao nosso alunado e acabamos por pecar em homogeneizar aquilo que estruturamos, negando a experiência de nossos discentes, assim como a sua subjetividade. Cada ser antes de chegar à classe traz em si a sua cultura que é comungada por todos os indivíduos que partilham do processo de ensino-aprendizagem. $O$ currículo é um diálogo de cada sujeito com o mundo e consigo mesmo (LOPES e MACEDO, 2011). O currículo é o mecanismo que dará subsídios para que o aluno entenda a natureza de suas próprias experimentações. Apesar de o CBEE dizer que é um conjunto sistematizado de elementos que compõem o processo educativo e a formação humana (ESPÍRITO SANTO, 2009, p.26.), o currículo nunca estará formado e deve ser gerado livremente levando em consideração o contexto de seu indivíduo e pluralidade de diferenças presentes no processo de ensino. Não existe uma estrutura curricular 'inacabada', cada um de nós, agentes e objetos do processo de ensino-aprendizagem, tem contribuição importante para a produção política curricular - produção essa que é constante e acontece no dia a dia. O currículo é um espaço de produção de identidades (PARAíSO, 2010), assim:

O pensamento curricular é, na contemporaneidade, um pensamento identitário. Buscamos responder no currículo: 'o que é mesmo?' Queremos saber o que é um currículo por competências? Falamos das semelhanças entre o currículo por competências e o currículo por objetivos. Procuramos identificar currículos póscríticos e distingui-los dos críticos. Apontamos semelhanças e diferenças entre o currículo oficial e o alternativo. Queremos saber o que é um currículo multicultural. Queremos saber o que é mesmo um currículo organizado por projetos de trabalhos. O que é um currículo tradicional ou construtivista? O que é um currículo escolar e um currículo de outros artefatos? Olhamos para a variedade de pensamentos existentes, de coisas, de indivíduos, de práticas sociais procurando classificar, encontrar a unidade, aquilo que as identifica: a identidade. Buscamos o comum sob a diferença (PARAíSO, 2010, p. 591).

Nessa perspectiva, apreendemos que as atuais teorias acerca dos componentes curriculares consideram DIFERENÇAS: a sexualidade, o gênero, a raça, o contexto de cada aluno - dando ao currículo um caráter multicultural como resposta a este estudante multifacetado. Ao tratar de sexualidade, de forma explícita ou não, nos processos de ensino aprendizagem não pode existir a preponderância de um tipo de sexualidade. Se durante os procedimentos de ensino, o professor se limita às particularidades de um tipo de sujeito, o 
profissional não alcança os outros que não se encaixam neste viés. Cabe ao professor promover ao sujeito a compreensão de suas vivências.

O corpo e língua são instrumentos políticos, assim como as roupas que o vestem um sujeito e a sexualidade que o envolve. E o currículo é uma arena política (MOREIRA E TADEU, 2011) que lapida a ideologia e a cultura pessoal de cada ser.

O currículo é o dia a dia na escola, colocando em voga as diferenças daqueles que compõe a realidade de um educandário. Nós, educadores, não podemos "fazer vista grossa" às subjetividades de nossos estudantes, porque isso seria negligência social - fomentadora de práticas de exclusão e discriminação.

Nos dias de hoje, o currículo é uma ação discursiva: tornando o aluno capaz de discorrer sobre aquilo que ele pensa, fazendo-o entender a natureza de suas experiências. $O$ professor, independente da matéria que leciona, promove o poder de criar sentidos e hegemonizá-los. Os discursos pedagógicos e curriculares cristalizados estão desestabilizados e não são pertinentes aos indivíduos da contemporaneidade.

Por que não utilizar representações na literatura nacional para instigar reflexões sobre o posicionamento do homem e da mulher na sociedade? Ao estudar o naturalismo brasileiro ou poemas contemporâneos é preciso mostrar poesia e narrativas com estereótipos referentes à sexualidade para que os alunos tenham contato com outras sexualidades que coexistem juntamente da heterossexualidade para que eles percebam que essa coexistência permeia também pela sociedade - com o intuito de desconstruir valores antes instituídos.

Houve tempo que a teoria literária ignorava as literaturas de caráter gay (SILVA, 2012) e feminina, o que contribuiu para esse apagamento para as análises literárias na escola de obras onde a sexualidade mais se ressalta. Numa perspectiva lógico-discursiva a sexualidade no Ensino Médio pode ser estudada por meio de debates que a veja além das identidades vistas como normativas. Debates esses que podem surgir também nas aulas de gramática, como por exemplo, nos estudos dos pronomes e variações linguísticas - mas é preciso que seja um trabalho bem planejado para que sejam descontruídos preconceitos e não reforçados.

\section{Procedimentos metodológicos: Pesquisa Bibliográfica e Experiência de grupo focal}

Para compor o corpus deste artigo foram utilizados dois procedimentos metodológicos: grupo focal e pesquisa bibliográfica, esta se deu com aporte teórico que trata de sexualidade, currículo e experiência docente, enquanto o primeiro é um tipo de coleta de dados por indivíduos de um contexto comum e baseia-se numa pesquisa qualitativa - segundo Meksenas (2002), cujo trabalho que não se preocupa com a generalização das conclusões obtidas a partir do exame da realidade abordada - acerca do dia a dia de professores de 
português ao abordarem a sexualidade humana em sala. A pesquisa foi delimitada ao Ensino Médio.

Grupos focais são procedimentos metodológicos de pesquisa que fazem uso de troca de experiências entre indivíduos com mesmas características para se discutir um determinado tópico, a técnica visa à coleta de dados a partir das vivências desses sujeitos. Fica exposto que essa busca sobre as percepções de professores de língua portuguesa acerca da sexualidade em sua atuação em sala de aula não tem apenas cunho educativo, mas também social e político.

Montar um grupo foi um trabalho árduo, pois o município onde foi realizado o procedimento em lócus fica no interior do estado e possuía até então professores e gestores com pensamentos retrógrados e reprodutores de preconceitos. Ecoporanga-ES possui seis escolas da Rede Estadual e duas delas não ofertam o Ensino Médio.

Primeiramente, a possível escola para ser local de pesquisa e realização do grupo focal seria aquela que tivesse um número considerável de professores de português. Sabendo que uma dessas escolas no ano de 2016 fez um belo trabalho sobre diversidade, inclusive organizado por um dos professores de português que esteve presente no meu grupo focal, procurei a gestão escolar.

O diretor desta instituição foi abordado e a ele fora explanado a temática do trabalho. Foi esclarecido que nomes de aluno, educadores e nem o nome da escola apareceria na pesquisa pronta. Foram uma hora e quarenta minutos dialogando no dia 13 de fevereiro de 2017 sobre a temática supracitada e a metodologia de pesquisa, contudo, ele achou inviável, porque tinha sido oprimido pela comunidade local por causa da experiência do ano letivo passado, quando alguns professores abordaram a diversidade cultural com seus educandos. Este diretor sugeriu que eu procurasse o outro colégio da "Sede" e afirmou que o mesmo teria a quantidade de professores necessários para o meu trabalho.

A outra Unidade Escolar do centro atua com tempo integral e pertence a um programa que muitos consideram como "vitrine" do último governo estadual - um modelo denominado 'Escola Viva'. A direção desta escola tida como "viva" foi contactada por telefone, porém, o procedimento de pesquisa não foi autorizado porque era a semana de acolhimento dos alunos: teria uma reunião de pais na quinta-feira, 23/02, e na sexta a comemoração do carnaval daquele ano. Logo, nesse momento seria inviável que a Instituição cedesse um momento entre 55 min e $1 \mathrm{~h}: 30 \mathrm{~min}$ para o método investigativo.

Inicialmente, o andamento do grupo para a pesquisa seria numa quinta-feira, porque na Rede de Ensino Estadual, geralmente, os planejamentos são divididos por área de conhecimento. A disciplina de língua portuguesa pertence à área de Linguagens e os PLs individuais e coletivos são feitos todas as quintas. Mas não conseguiu-se entrar em acordo com os colégios, o que foi inadmissível. 
Por isso, a organização desse grupo focal com professores se deu na casa do pesquisador no dia 07 de março daquele ano, às 19h30min. O encontro foi realizado com cinco sujeitos: investigador mais quatro professores de português. Serão chamados de Pedro, Paula, Sara e Keila - os pseudônimos manterão discretas suas identidades. $O$ áudio foi gravado no celular para ficar mais cômodo transcrevê-la no artigo.

Segue apresentação dos componentes desse diálogo: a) Pedro: Era o mais comunicativo do grupo, se formou em 2015 e assumiu um posto de trabalho efetivo em julho de 2016 aqui em Ecoporanga. É natural de Guarapari e se graduou em Letras/Português pela Universidade Federal de Ouro Preto, a UFOP. Até a época da pesquisa trabalhava em apenas uma das escolas do centro, porém, no mês de abril conseguiu se localizar provisoriamente na Escola Viva do município de Guaçuí-ES; b) Keyla: Trabalha pela rede desde 2012, em Regime de Designação temporária. Em 2017 trabalhava apenas na escola de um distrito, chamado de Cotaxé e com o Ensino Fundamental. É graduada pela Multivix-Nova Venécia em português, inglês e espanhol e é natural de Ecoporanga; c) Paula: Trabalhava no distrito de Imburana e lecionando português para uma turma de $8^{\circ}$ ano do Ensino Fundamental e espanhol para os alunos de $3^{a}$ série do Ensino Médio. Numa das escolas da "Sede" lecionava as disciplinas de português para turmas dos níveis médio e fundamental. É habilitada desde 2010 pela Multivix-Nova Venécia em português, inglês e espanhol. É natural deste município e trabalhava em Regime de Designação Temporária; d) Sara: Também graduada nas línguas portuguesa, espanhola e inglesa pela Multivix-Nova Venécia, é licenciada desde 2012 e natural de Vila Pavão-ES. Assumiu sua cadeira como efetiva em julho do ano passado e atuava na escola do distrito de Joassuba.

A conversa durou cerca de uma hora, inclusive menos que o planejando. É preciso ressaltar que os colaboradores dessa pesquisa assinaram um termo de consentimento livre e esclarecido sobre esse trabalho. Essa realização não foi mal elaborada por não ter sido dentro de uma escola, inclusive isso é um dado importante para a pesquisa, porque se percebe que esse aparelho social se submete às regras tradicionais que moldam a sociedade e fica desajeitada diante da realidade moderna, muitas vezes negligenciando-a (MASSCHELEIN; SIMONS, 2014).

\subsection{Desenvolvimento de grupo focal}

Essa conversa se embasou em três perguntas relacionadas à sexualidade, à formação e ao trabalho docente: 1) O que entendem por sexualidade?; 2) A formação que tiveram em algum momento trouxe alguma discussão a respeito dessa temática?;3) Percebem que o tema sexualidade aparece em algum ponto das matérias lecionadas em Língua Portuguesa? E quando isso acontece? 
A tarefa teve alguns obstáculos: não durou o tempo pretendido e às vezes a discussão perdia o foco. Talvez se essa atividade tivesse sido realizada no ambiente escolar, o grupo se manteria com o caráter diretivo.

Antes de iniciar a conversa, a professora Sara disse que não entendia muito da temática. Para facilitar o processo de compreensão, Pedro nos mostrou o que ele entende por gênero e sexualidade:

O gênero de uma pessoa vai além do campo biológico, porque o mesmo pode se diferenciar da orientação sexual de um indivíduo. É a identificação do sujeito em sociedade. Já a sexualidade, na minha visão, é tudo aquilo ao campo dos instintos sexuais e do desejo, começando na puberdade e é uma construção cultural e de instinto biológico. Uma prática humana moldada pela moral e por isso é um assunto polêmico, eu diria que é a "maçã" proibida (PROFESSOR PEDRO).

Assim, foi lançado o primeiro tópico: O que vocês entendem por sexualidade?

A gente percebe que a sexualidade é confundida com o erotismo e as relações sexuais, tem toda a capa revestida pela religião. Por isso é tão difícil trabalhar esta temática e esse trabalho fica a encargo da disciplina de biologia por tratar de questões do corpo e da reprodução (PROFESSORA PAULA).

Olha, para mim a sexualidade está muito ligada a essa nossa necessidade de dar e receber afeto, de relacionar com outras pessoas para dar e receber prazer. Prazer no sentido mais amplo da palavra, indo além do campo sexual mesmo (PROFESSORA SARA).

Entendo a sexualidade como o sinônimo de gênero. E recorri à internet porque não entendo muito. Pelo que pesquisei, a sexualidade remete aos traços mais íntimos de uma pessoa, que acaba sendo um produto daquilo que ele está vivendo (PROFESSORA KEILA).

Percebe-se que os colegas de sala de aula entendem que a sexualidade é uma particularidade daquilo que o indivíduo sente em seu íntimo e a enxergam como uma subjetividade exposta naturalmente, mesmo ainda sendo um tabu para a nossa realidade. Quando a professora Paula disse que na escola essa temática fica na responsabilidade da matéria de biologia, Pedro contou uma ocorrência na escola que ele atua, mas antes de ele começar a trabalhar nela:

Tive um relato de um professor de biologia que ao trabalhar prevenção sexual, pediu que os alunos abrissem as camisinhas para que colocasse no dedo para que aprendessem a usar. E essa, inclusive é uma orientação de um manual da própria Secretaria Estadual de Educação sobre sexualidade e sexo, manual que é fartamente distribuído em escolas estaduais para se evitar a gravidez na adolescência e na escola. Só que a comunidade não entendendo isso, mesmo 
sendo uma orientação estadual, impressa e assinada pelo Secretário, entendeu que o professor estava insinuando que as meninas já estivessem transando. Foi relato que tive de um professor que sofreu perseguição. A escola tem muita dificuldade de trabalhar esse tema, como tantos outros temas e a sexualidade é algo importantíssimo na vida dos indivíduos, não podemos fingir que não temos esses instintos e tratar a coisa com neutralidade criminosa (PROFESSOR PEDRO).

E pelo diálogo, nota-se que em Ecoporanga há um bloqueio na comunidade a respeito da sexualidade, que é equiparada às atividades sexuais dos sujeitos. Partindo para o segundo tópico, foi questionado se na formação deles houve em algum momento foi trazida alguma discussão a respeito dessa temática.

Na formação informal todos têm contato com a temática, seja por meio de diversos tipos de textos, músicas e vivências do dia a dia. Mas na realidade, todos nós estamos habituados a fazer 'vistas grossas' e ignorar e situações que nos causam certa estranheza quando tocamos nesse assunto. Principalmente nas escolas (PROFESSORA PAULA).

No meu tempo de faculdade quase não tocamos nesse assunto. Nem me lembro até! Falávamos de diversidade uma hora ou outra na disciplina de Educação Especial. Nem na disciplina de Práticas de Ensino a sexualidade foi abordada. O que sei li em artigos, mas não me aprofundei no assunto (PROFESSORA KEILA).

$\mathrm{Na}$ faculdade nem sequer ouvi falar de sexualidade! $E$ olha que eu me formei em 2012. Quando tenho a necessidade de fazer algum trabalho em sala, eu me planejo por conta própria e busco na internet filmes e textos que podem ter o tema, mesmo que de uma forma mais suave. Se eu me lembro bem, quando trabalhei em Nova Venécia em 2004, a SEDU deu uma formação chamada de "Adolescência, sexualidade e gravidez", mas era para professores de Ensino Fundamental. A sexualidade foi um dos temas. Mas foi uma formação muito fraca e não deu base para muitas reflexões. Principalmente para o trabalho em sala de aula e olha que era uma formação de professores. O ocorrido foi na época em que ela morava em São Gabriel da Palha, mas esta formação aconteceu na Superintendência do município de Nova Venécia (PROFESSORA SARA).

Apesar de terem se graduado em tempos distintos, sua formação num geral tem falhas no trabalho envolvendo sexualidade, porque o tema quase não foi abordado. Dando continuidade, o terceiro tópico da conversa é voltado para o cotidiano durante o ensino: Como vocês percebem que o tema sexualidade aparece em algum ponto das matérias lecionadas em Língua Portuguesa? E quando isso acontece?

É um tema muito interessante, eu até poderia trabalhá-lo em sala. Mas os alunos não estão preparados ainda e eles não têm maturidade. Acabo não trabalhando porque acabam interpretando tudo errado. E para nós que trabalhamos em distrito as chances são grandes para arrumarmos transtornos na nossa vida profissional (PROFESSORA PAULA). 
Eu trabalho numa escola de interior, a presença da família acaba ás vezes sendo mais efetiva. Eles são muito religiosos, eu não me arrisco a trabalhar um tema dessas (PROFESSORA SARA).

Trabalhei o tema no ano passado, no Ensino Médio, a partir de oficinas que eu expus música, fotografia, publicidade. Mas percebi que os alunos tinham um bloqueio e não se sentiam à vontade para falar, principalmente pelo fato de que a sala ser composta por meninos e meninas, e aqui pela questão cultural esses universos são mais separados do que possam parecer, mesmo sendo adolescentes. Mas o que percebo que a escola lança olhares de preconceito sobre o tema e as pessoas que não estejam diretamente envolvidas, mas acompanham seus filhos na escola, também têm seus preconceitos e acabam impondo seus interesses privados e dogmáticos acima dos interesses públicos (PROFESSOR PEDRO).

A sexualidade aparece sim nos conteúdos de língua portuguesa e ainda eixos do CBC de maneira bem específica. Mas muitos professores de português evitam essas abordagens por não saber como tratar essa questão adequadamente. Quando é preciso fazer algum trabalho do tipo, arrisco. Isso é mais fácil no Ensino Médio, apesar de termos alunos com a vida sexual ativa, a gente percebe que eles têm sexualidade mal orientada, têm muitas dúvidas a respeito (PROFESSORA SARA).

Eu acho muito difícil envolver a sexualidade abertamente para os meninos, também tenho medo ser mal interpretada, não só pelos meus alunos, mas pelas famílias deles. Parece que não cabe colocar os domínios da sexualidade dentro da escola (PROFESSORA KEILA).

Com o grupo focal viu-se que os participantes reconhecem e veem o quão pertinente é promover um trabalho que se embase na sexualidade, mas também o quanto é difícil: o contexto em que estavam inseridos os engessava. Parece que tudo que destoa dos interesses dos dominantes deve ser controlado - inclusive aquilo que é discutido na escola.

Diante de tantas dificuldades, percebe-se que a sexualidade precisa ser trabalhada com os alunos discretamente.

\section{Considerações finais}

Observando o contexto em que atuamos, acredita-se que o trabalho envolvendo a sexualidade no cotidiano escolar muitas vezes precisa ser feito sutilmente devido à repressão dos alunos sobre a temática e por a escola e a sociedade não estarem preparadas para lidar com um assunto tão íntimo. Viu-se também que a sexualidade ainda está intimamente ligada ao campo da atividade sexual, quando essas configurações permeiam um ser em toda sua amplitude.

Vemos que que o currículo de língua portuguesa da Rede Estadual do Espírito Santo, contempla a sexualidade de forma superficial, sendo que a mesma poderia ser aproveitada tanto em conteúdos de gramática, quanto os de literatura. 
$\mathrm{Na}$ atualidade esse é o conceito curricular que mais condiz: o cotidiano escolar juntamente das diferenças e subjetividades dos alunos que o compõem. Corpo, linguagem e sexualidade são os artifícios políticos de um indivíduo e um currículo precisa valorizar a cultura pessoal de cada ser. E o ensino de português precisa ser discursivo, dialogado e reflexivo para que contribua para a idealização politizada do educando.

Grupos focais podem gerar um volume de informações expressivas em um curto espaço de tempo, no entanto, essa pesquisa foi de extrema valia, pois podemos notar por meio das percepções desses professores que existem inquietações sobre o trabalho docente envolvendo a sexualidade. Essa prática não aconteceu numa unidade escolar, porém essa situação foi um fator importante para ficar perceptível o ignorar da temática dentro das escolas daquela região. É, de maneira negativa, surpreendente não realizar o grupo focal numa escola por causa da temática, sendo que a escola é um ambiente de interesses públicos e multifacetados. É um absurdo negligenciar as particularidades do outro.

As percepções coletadas sobre o ensino da sexualidade são comuns a todos os presentes no diálogo: o bloqueio dos alunos, a opressão da equipe escolar, a falta de formação docente e continuada na perspectiva dessa temática. A impressão tida é que a sexualidade está fora dos domínios da escola e que esta não se compromete com os interesses públicos.

\section{Referências}

CARVALHO, ALBERTO Cezar de. Os desafios enfrentados pelos docentes para o ensino de informática diante das novas tecnologias de informação e comunicação. Dissertação (Mestrado em Educação) - Universidade Estácio de Sá, Rio de Janeiro- RJ, 2011.

DELEUZE, Gilles. Espinosa: filosofia prática. São Paulo: Escuta, 2002.

Espírito Santo (Estado). Secretária da Educação. Currículo Básico Escola Estadual. Guia de implementação / Secretaria da Educação - Vitória: SEDU, 2009.

FOUCAULT. Michel. História da sexualidade 3: Cuidado de si. 1ª Edição. São Paulo: Paz e Terra, 2014.

LOURO, Guacira Lopes. Gênero, sexualidade e educação: das afinidades políticas às tensões teórico-metodológicas. Educação em Revista. Belo Horizonte. n. 46. p. 201-218. dez. 2007. LOPES, Alice Casimiro; MACEDO, Elizabeth. Teorias de currículo. São Paulo: Cortez, 2011. MASSCHELEIN, Jan; SIMONS, Maarten. Em defesa da escola: uma questão pública. 2 ed. Belo Horizonte: Autêntica, 2014.

MEKSENAS, Paulo. Pesquisa social e ação pedagógica: conceitos, métodos e práticas. São Paulo: Edições Loyola, 2002. 
OSTERMANN, Ana Cristina; FONTANA, Beatriz. Linguagem, gênero, sexualidade: clássicos traduzidos. São Paulo: Parábola Editorial, 2010.

PARAÍSO, Alves Marlucy. Diferença no currículo. Cadernos de Pesquisa, v.40, n.140, p. 587604, maio/ago. 2010.

SILVA, Antonio de Pádua Dias da. A história da literatura brasileira e a literatura gay: aspectos estéticos e políticos. Maceió: Editora, 2012, p. 83-108. 